\title{
Fabric Defect Detection by Fourier Analysis
}

\author{
Chi-ho Chan, Student Member, IEEE, and Grantham K. H. Pang, Member, IEEE
}

\begin{abstract}
Many fabric defects are very small and undistinguishable, which makes them very difficult to detect by only monitoring the intensity change. Faultless fabric is a repetitive and regular global texture and Fourier transform can be applied to monitor the spatial frequency spectrum of a fabric. When a defect occurs in fabric, its regular structure is changed so that the corresponding intensity at some specific positions of the frequency spectrum would change. However, the three-dimensional frequency spectrum is very difficult to analyze. In this paper, a simulated fabric model is used to understand the relationship between the fabric structure in the image space and in the frequency space. Based on the three-dimensional frequency spectrum, two significant spectral diagrams are defined and used for analyzing the fabric defect. These two diagrams are called the central spatial frequency spectrums. The defects are broadly classified into four classes: 1) double yarn; 2) missing yarn; 3 ) webs or broken fabric; and 4) yarn densities variation. After evaluating these four classes of defects using some simulated models and real samples, seven characteristic parameters for a central spatial frequency spectrum are extracted for defect classification.
\end{abstract}

Index Terms-Defect detection, Fourier analysis, quality assurance, textile industry, texture characterization.

\section{INTRODUCTION}

I N THE TEXTILE industry, before any shipments are sent to customers, inspection is needed for maintaining the fabric quality. Srinivasan et al. [1] have stated that the price of secondquality fabric is only $45 \%-65 \%$ of that of first-quality fabric. However, the current inspection process still depends mainly on human sight. The nature of this work is very dull and repetitive. Moreover, there could be many human errors in this process. According to some studies, human visual inspection can only catch around $60 \%-75 \%$ of the significant defects [2]. Therefore, in order to lower the cost of the inspection process and to increase the competitive advantage of the products, it is necessary to automate the inspection process.

In this paper, the central spatial frequency spectrum approach is introduced and examined. This method would reduce the computational time for defect detection and provide more parameters for defect classification. Before introducing this method, the characteristics of fabric structure in the frequency spectrum will be examined and some defect examples will be described. After that, the procedures of the method and experimental results will be discussed.

Paper MSDAD-S 00-10, presented at the 1999 Industry Applications Society Annual Meeting, Phoenix, AZ, October 3-7, and approved for publication in the IEEE TRANSACTIONS ON INDUSTRY APPLICATIONS by the Industrial Automation and Control Committee of the IEEE Industry Applications Society. Manuscript submitted for review October 15, 1999 and released for publication May 6, 2000

The authors are with the Department of Electrical and Electronic Engineering, The University of Hong Kong, Hong Kong (e-mail: chichan @eee.hku.hk).

Publisher Item Identifier S 0093-9994(00)07614-3.
Zhang et al. [3] have introduced two approaches to detect defects: gray-level statistical and morphological methods. Lanes [4] has defined a number of convolution masks to detect the defect. These methods, which depend on intensity change on the fabric image, can only capture the significant defects such as knot, web, and slub. However, faultless fabric has a periodic regular global structure. The occurrence of a defect in the fabric means that the regular structure has been destroyed. Therefore, the fabric defect can be detected by monitoring fabric structure. Ciamberllini and his colleagues have used the optical Fourier transform to monitor the fabric structure. Their methods can be classified as follows: fixed masks or structured detectors, adaptable filters [5], electronic elaboration of the image [6], and binary histogram [7]. Fixed masks, structured detectors, and adaptive filters are the fixed optical filters placed over the photodetector active area. They are composed of periodic array transparent and opaque zones, and their locations depend on the peak of the fabric diffraction image. When a defect occurs, some localized peaks in the diffraction image will be passed to the sensor. However, this type of operation requires careful alignment and different fabric types require different filters. The method of electronic elaboration is based on the subtraction of the reference image of faultless fabric from that of the fabric under inspection. The binary histogram method is based on a summation of the gray-level pixels, which have gray level greater than a threshold. The threshold is defined according to the fabric type and system sensitivity. Optical processing is very expensive and requires careful calibration. Also, this method could not recognize fabric with higher fabric density.

Another class of methods is dependent on digital image processing. Wood [8] has used Fourier and associate transform to characterize carpet patterns. Ravandi and Toriumi [9] have used Fourier transform analysis to measure fabric appearance. Fabric surface characteristics, fill, and warp yarns for plain-weave cotton fabric were also discussed. Escofet et al. [10] have used the angular correlation of the Fourier spectra to evaluate fabric web resistance to abrasion. Sari-Saraf and his colleagues [11] have used Fourier transform to detect fabric defects. Their approach examines and performs a one-dimensional signature diagram in the two-dimensional spectrum. The signature diagram is obtained by integrating the points within each ring in the two-dimensional spectrum. The rings are concentric with different radii, and they are used to monitor the fill and wrap densities. The idea of this approach is similar to the concentric ring filter in optical processing [5]. The main advantage of this approach is that it is less sensitive to the background noise (intensity source variation). Also, it is more effective for revealing a defect due to dimensional changes in the structure of the fabric. This method can recognize the 


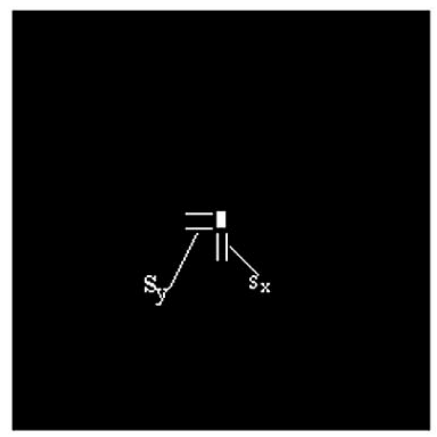

(a)

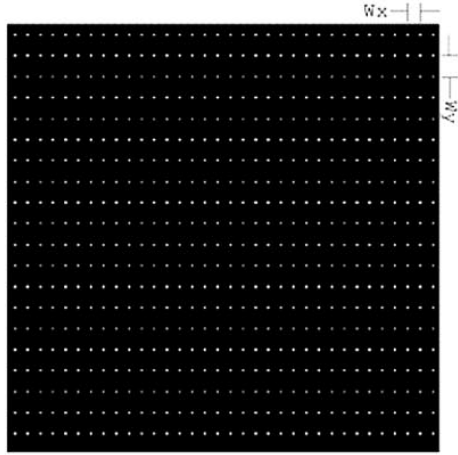

(b)

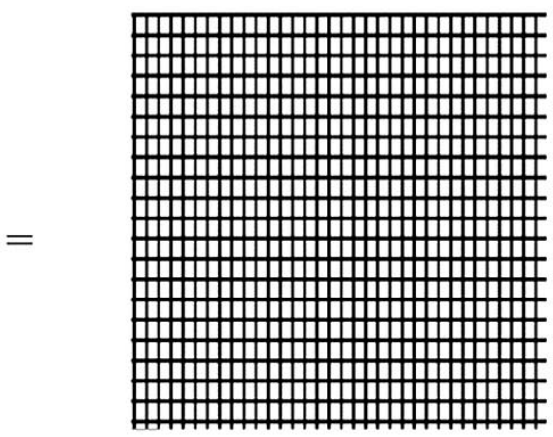

(c)

Fig. 1. (a) Fabric structure gap. (b) Fabric gap location. (c) Simulated faultless fabric

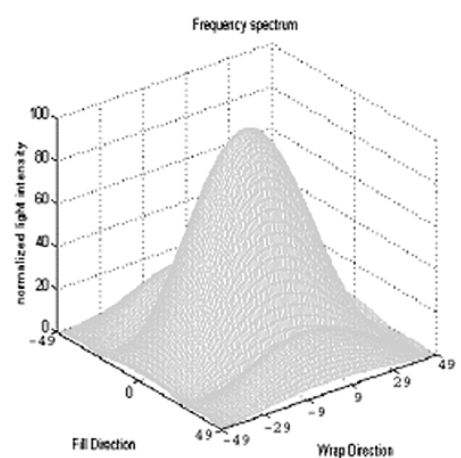

(a)

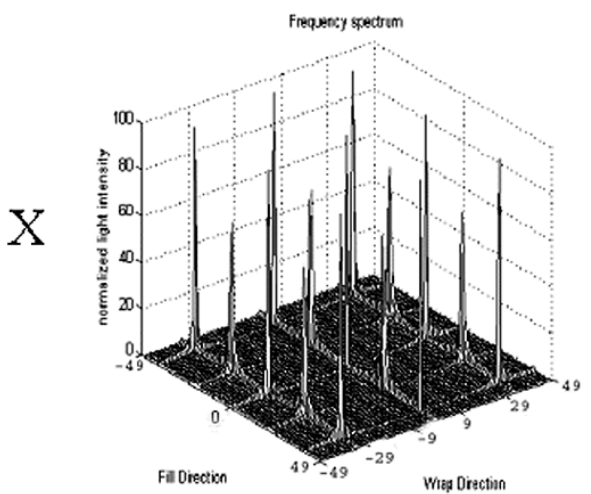

(b)

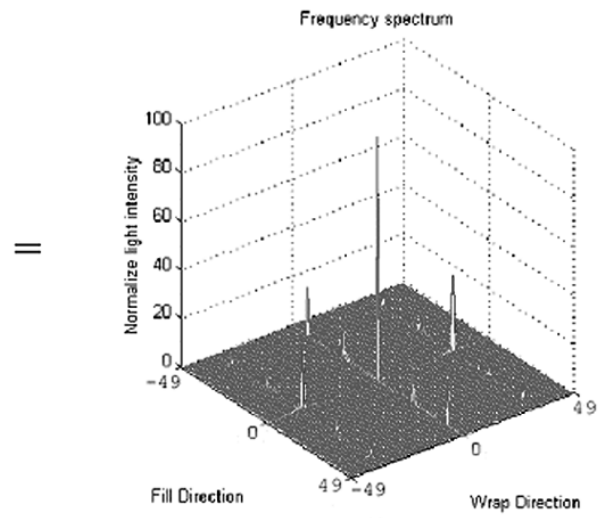

(c)

Fig. 2. Magnitude of frequency spectrum (central portion). (a) Fabric structure gap. (b) Fabric gap location. (c) Simulated faultless fabric.

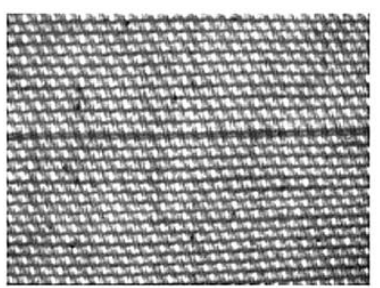

(a)

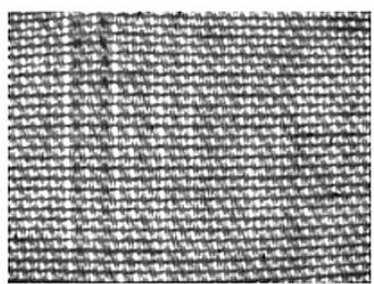

(b)

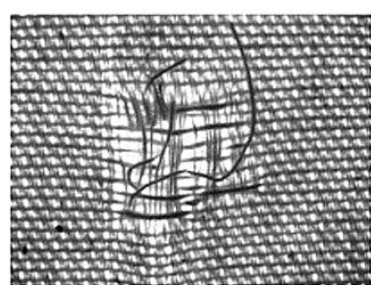

(c)

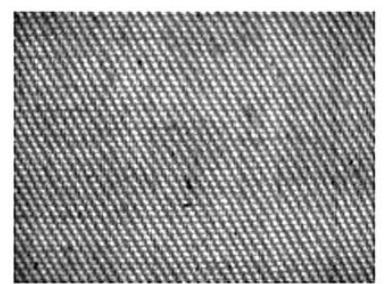

(d)

Fig. 3. Fabric defect samples. (a) Double yarn. (b) Missing yarn. (c) Broken fabric. (d) Variation of yarn.

high fabric densities by using the zoomed camera, but long computational time is expected.

\section{BACKGROUND KNOWLEDGE}

\section{A. Fourier Transform}

Fourier theorem states that any signal can be represented by the sum of the sine and cosine wave with various amplitudes and frequencies. That is, the relationship between a repetitive, regular, and uniform fabric pattern in the image space and its spectrum in the spatial frequency can be linked by operating two-dimensional Fourier transform. Let a two-dimensional image be $f(x, y)$, which is a real function representing the gray level in $x, y$ spatial coordinates, and let the image width and image length be $N$. Let $F(n, m)$ denote the Fourier transform of $f(x, y)$ with $n$ and $m$ spatial frequencies. The general equation of two-dimensional discrete Fourier transform is

$$
F(n, m)=\frac{1}{N^{2}} \sum_{y=0}^{N-1} \sum_{x=0}^{N-1} f(x, y) * e^{-j 2 \pi(x n+y m) / N} .
$$

The computational time for Fourier transform is generally long. For two-dimensional discrete Fourier transform, it is proportional to the second order of the image size. In order to reduce the computation time, fast Fourier transform (FFT) is used. FFT is a discrete Fourier transform with some reorganization that can save an enormous amount of time. For one-dimensional FFT, the computation time is $N \log _{2} N$. Because of the separable transform [12], [13] being used to perform the two-dimensional transform, the computation time is proportional to $2 N^{2} \log _{2} N$. One of the advantages for the spatial frequency spectrum approach is the translation property of Fourier transform [12], [13] 


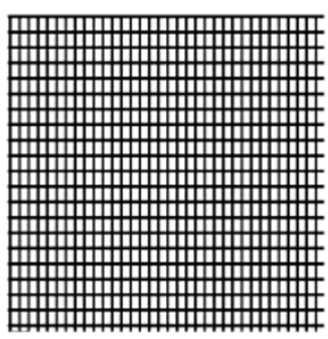

(a)

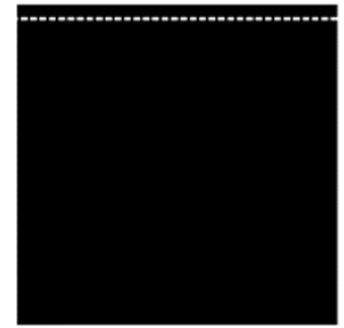

(b)

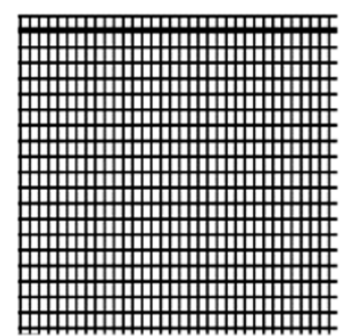

(c)

Fig. 4. (a) Faultless fabric $f(x, y)$. (b) Rectangle series function $d(x, y)$. (c) Double fill defect.

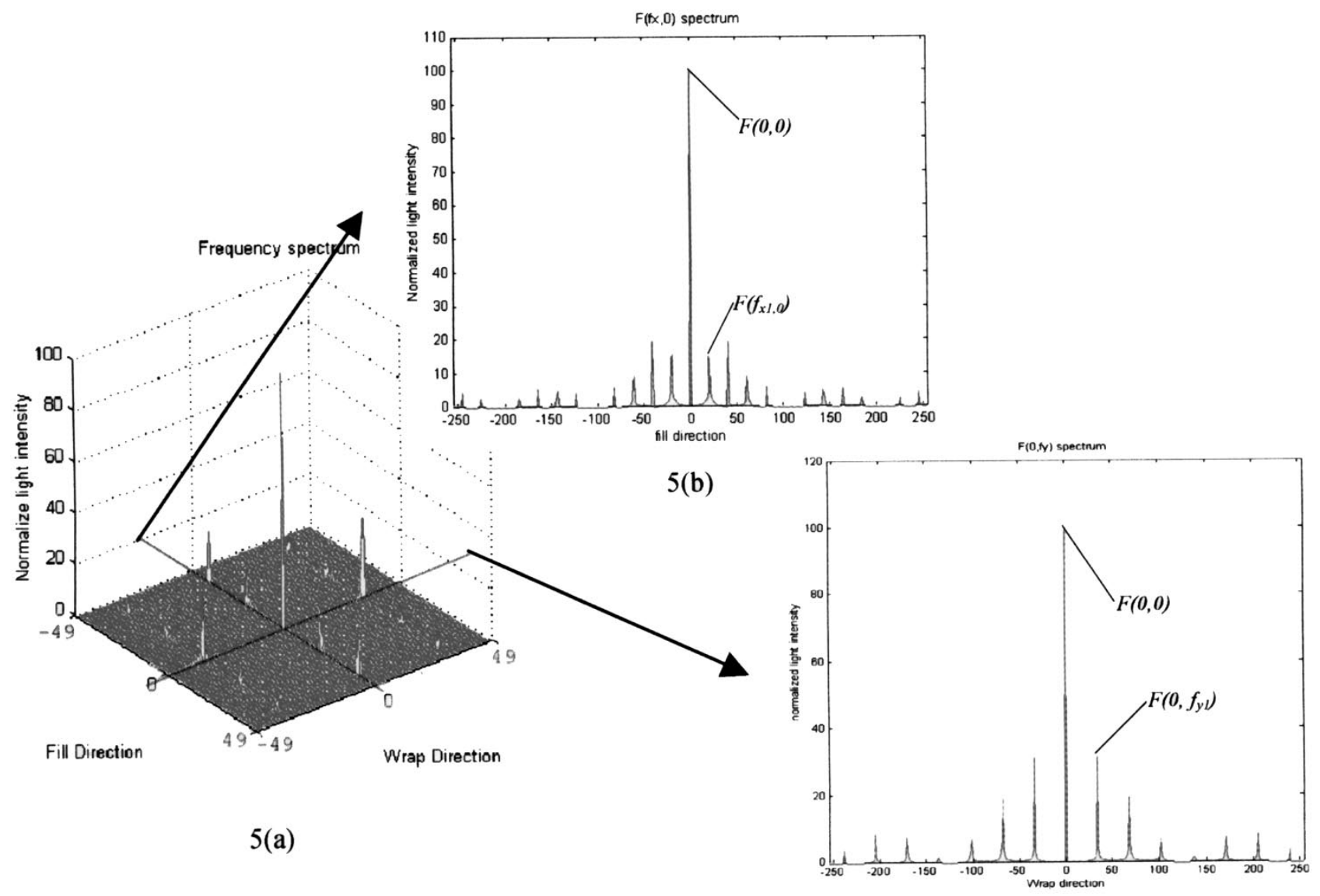

$5(\mathrm{c})$

Fig. 5. (a) Portion of faultless fabric frequency magnitude spectrum. (b) Fill direction frequency spectrum. (c) Wrap direction frequency spectrum.

that is shown in (2), which means that the magnitude of frequency spectrum does not change when the fabric is moved up. The spectrum is only varied by the change of fabric structure

$$
f(x-a, y-b) \Leftrightarrow F\left(f_{x}, f_{y}\right) * e^{-j 2 \pi\left(f_{x} a+f_{y} b\right) / N} .
$$

tude of frequency spectrum. A two-dimensional discrete convolution theorem is involved for constructing a simulated fabric. Let $h$ and $g$ be the input and output image, respectively, and $t$ is a convolution mask. Therefore, the convolution denoted by $\otimes$ is the computation of weighted sums of the image pixels with the convolution mask, which is shown in

\section{B. Characteristics of Fabric Structure in the Magnitude of Frequency Spectrum}

A simulated frequency spectrum should be examined for understanding the characteristics of fabric structure in the magni-

$$
\begin{aligned}
g(x, y) & =t(x, y) \otimes h(x, y) \\
& =\sum_{\tau_{1}=0}^{x} \sum_{\tau_{2}=0}^{y} t\left(\tau_{1}, \tau_{2}\right) h\left(x-\tau_{1}, y-\tau_{2}\right) .
\end{aligned}
$$


The simulated pattern of a faultless fabric is shown in Fig. 1(c). The faultless fabric image pattern $f(x, y)$ is modeled as shown in

$$
f(x, y)=\operatorname{rect}\left(x / s_{x}, y / s_{y}\right) \otimes \sum_{n_{1}=-\infty}^{\infty} \sum_{\substack{\left.n_{2}=-\infty \\ y-n_{2} w_{y}\right)}}^{\infty} \delta\left(x-n_{1} w_{x}\right.
$$

where

$$
\operatorname{rect}(u, v)= \begin{cases}1, & |u| \leq 0.5 \text { and }|v| \leq 0.5 \\ 0, & \text { otherwise }\end{cases}
$$

and where $\delta(u, v)=\delta(u) \delta(v)$, which is the two-dimensional Dirac $\delta$ function.

The first part of (4) is a function that describes the fabric structure gap [Fig. 1(a)], where $s_{x}$ is the width of the gap and $s_{y}$ is the height of the gap. Let $w_{x}$ be the wrap period and $w_{y}$ be the fill period. The second part is the impulse function that models the location of the gap in the fabric [Fig. 1(b)].

The Fourier transform of the convolution of two functions in an image space is equal to the product of their respective Fourier transforms as shown in

$$
\begin{aligned}
\left|F\left(f_{x}, f_{y}\right)\right|=\mid & s_{x} \cdot s_{y} \cdot \operatorname{sinc}\left(2 \pi f_{x} \cdot s_{x}\right) \cdot \operatorname{sinc}\left(2 \pi f_{y} \cdot s_{y}\right) \\
& \cdot\left[\frac{4 \pi^{2}}{w_{x} \cdot w_{y}} \sum_{n_{1}=-\infty}^{\infty}\right. \\
& \left.\cdot \sum_{n_{2}=-\infty}^{\infty}\left(2 \pi f_{x}-\frac{2 \pi n_{1}}{w_{x}}, 2 \pi f_{y}-\frac{2 \pi n_{2}}{w_{y}}\right)\right] \mid .
\end{aligned}
$$

The frequency spectrums of the corresponding figures of Fig. 1 are shown in Fig. 2. The envelope of the faultless fabric in frequency space shown in Fig. 2(c) is proportional to the envelope of the Fourier transform of the fabric structure gap as shown in Fig. 2(a). In fact, the shape of the envelope of Fig. 2(a) is affected by two parameters: $s_{x}$ and $s_{y}$. For example, if the structure gap $s_{x}$ and $s_{y}$ are increased, the envelope shape of Fig. 2(a) will be narrower. Referring to Fig. 1(b), the location of the impulse in the image space is inversely proportional to the impulse location in frequency space in Fig. 2(b). The distance between two impulses in Fig. 2(b) should be $1 / w_{x}$ in the horizontal axis and $1 / w_{y}$ in the vertical axis. These properties can aid to monitor the yarn densities in the two directions. For example, the density in the horizontal direction is equal to the distance between two impulses in the horizontal axis (i.e., $1 / w_{x}$ ) multiplied by the image width.

\section{Simulation of Fabric Defect}

In this paper, the defects are broadly classified into four classes: 1) double yarn; 2) missing yarn; 3) webs or broken fabric; and 4) yarn densities variation. Examples are shown in Fig. 3. The double yarn (fill) is a change of spatial periodicity on the vertical axis. The spectrum on the $f_{x}$ axis (fill direction) denotes the corresponding change of spatial frequency. In a simulated model of the double yarn, $D(x, y)$, shown in Fig. 4(c), the defect can be regarded as a subtraction from a faultless fabric [Fig. 4(a)] to a series of rectangle function, $d(x, y)[$ Fig. 4(b)]. By the distributivity property of the Fourier transform

$$
\begin{aligned}
F\{D(x, y)\} & =F\{f(x, y)-d(x, y)\} \\
& =F\{f(x, y)\}-F\{d(x, y)\}
\end{aligned}
$$

the defect in the frequency space can be formed by subtracting the faultless fabric frequency spectrum from the Fourier transform of the irregular structure function $d(x, y)$.

\section{Central Spatial Frequency Spectrum}

Due to the nature of the fabric structure, many defects would occur along the $x$ and $y$ axes, which means that those characteristics would appear on the wrap $\left(f_{y}\right)$ and fill $\left(f_{x}\right)$ direction in the frequency spectrum. In addition, a three-dimensional graph of the frequency spectrum is very difficult to analyze. The method of central spatial frequency spectrum is, therefore, proposed in this paper. This method extracts two diagrams along the $f_{x}$ and $f_{y}$ direction $\left(\left|F\left(f_{x}, 0\right)\right|\right.$ and $\left.\left|F\left(0, f_{y}\right)\right|\right)$ from the three-dimensional graph, which are shown in Fig. 5.

Seven significant features can be extracted in these two diagrams for describing defect characteristics. The equations of these parameters are as follows:

$$
\begin{aligned}
\mathrm{P} 1 & =F(0,0) \quad \mathrm{P} 2=100 \times F\left(f_{x 1}, 0\right) / F(0,0) \quad \mathrm{P} 3=f_{x 1} \\
\mathrm{P} 4 & =100 \times\left(\sum_{f_{x i}=0}^{f_{x 1}} F\left(f_{x i} / ; 0\right) / F(0,0)\right) \\
\mathrm{P} 5 & =100 \times F\left(0, f_{y 1}\right) / F(0,0) \quad \mathrm{P} 6=f_{y 1} \\
\mathrm{P} 7 & =100 \times\left(\sum_{f_{y i}=0}^{f_{y 1}} F\left(0, f_{y i}\right) / F(0,0)\right)
\end{aligned}
$$

where $f_{x 1}$ and $f_{y 1}$ correspond to the first harmonic frequency in their respective diagrams that are also shown in Fig. 5. The first feature $\mathbf{P 1}$ is the average light intensity of the image, which is used to characterize irregular fabric structure. Higher yarn density decreases the light intensity and $\mathbf{P 1}$ is decreased, and vice versa. P2, P3, and $\mathbf{P 4}$ are for detecting the horizontal (fill) threads structure, whereas P5, P6, and P7 are used to monitor the vertical (wrap) threads structure. Features $\mathbf{P 3}$ and $\mathbf{P 6}$ correspond to the first harmonic frequency and they are used to monitor the wrap and fill threads density in the image. When defects occur, the amplitude of harmonic frequencies plus other changes would appear in the central spatial frequency spectrum. Features $\mathbf{P 2}, \mathbf{P 4}, \mathbf{P 5}$, and $\mathbf{P 7}$ are used to describe and detect these characteristics. Those features are more concentrated on analyzing the region between the central peak and first peak (first harmonic frequency) because higher harmonic frequency components are significantly distorted in a real environment.

A defect such as double wrap is shown in Fig. 6(a). A comparison of the defect spectrum and faultless fabric spectrum are shown in Fig. 6(b) and (c), where the defect is denoted by the solid line and the faultless fabric is denoted by the crosses. Fig. 6(b) and (c) shows that the central peak value (P1) of the defect fabric is lower than that of the faultless fabric. This is because more vertical (wrap) threads are added in the faultless fabric, which leads to lower light intensity in the defect image as shown in Fig. 6(a). The double wrap defect is a change of spatial 

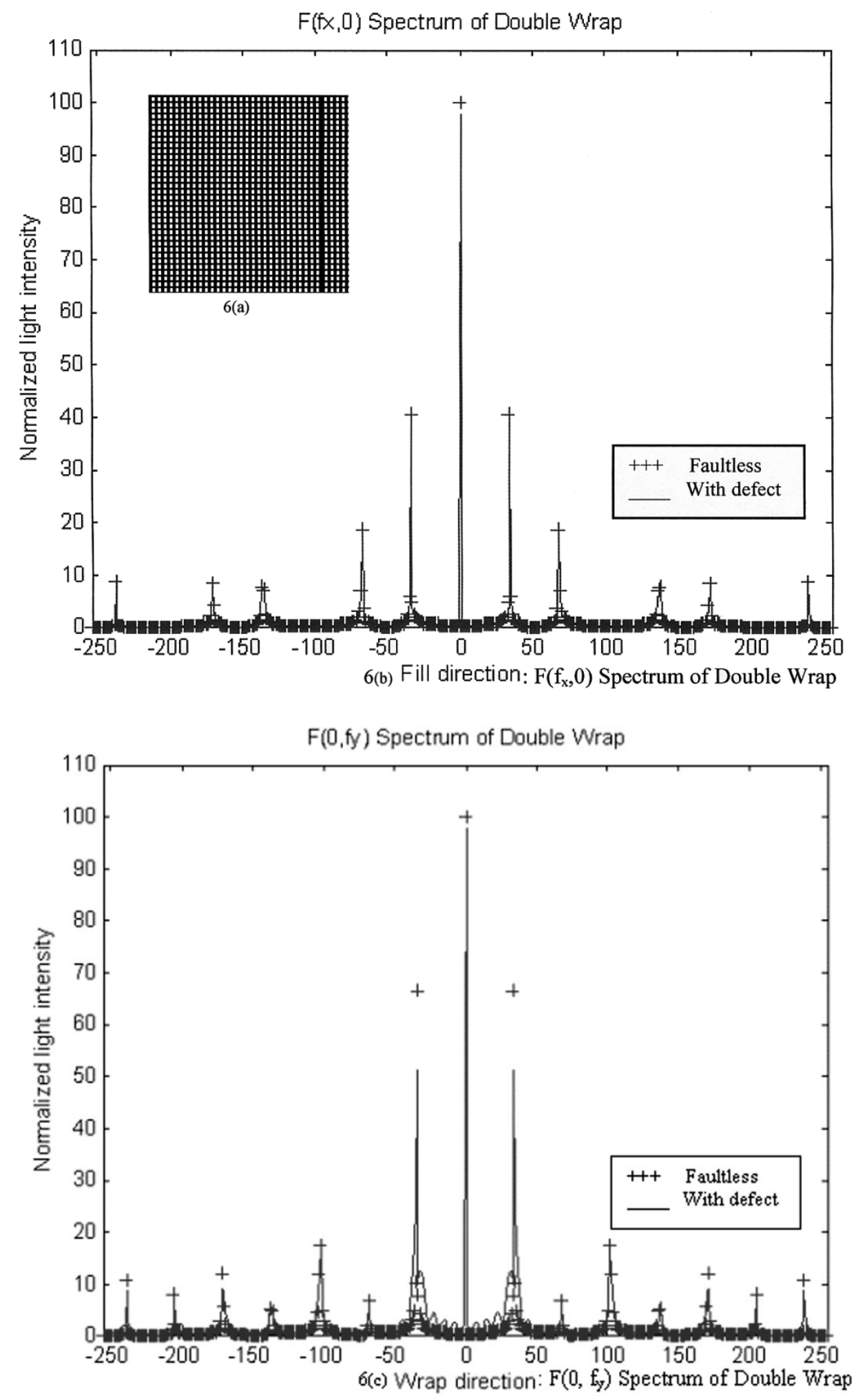

Fig. 6. (a) Double yarn. (b) Double yarn direction spectrum. (c) Double yarn wrap direction spectrum.

periodicity in the horizontal axis and, therefore, the $\left|F\left(0, f_{y}\right)\right|$ diagram [Fig. 6(c)] is changed mostly. In this diagram, the first peak value of the defect at $f_{y 1}=35$ are lower than the faultless fabric first peak values and ripples occur. Therefore, P5 should be lower and P7 should be higher. The first peak location $\left(\mathbf{P 6}=f_{y 1}=35\right)$ is a fundamental yarn frequency, which is proportional to the yarn density. In this example, $\mathbf{P 6}$ is almost unchanged, as expected. A summary is shown in the second row of Table I. With a similar interpretation, the double fill defect is a change of spatial periodicity in the vertical axis. Hence, the parameters P2 and P4 are changed because the defect mainly affects the $\left|F\left(f_{x}, 0\right)\right|$ diagram. 


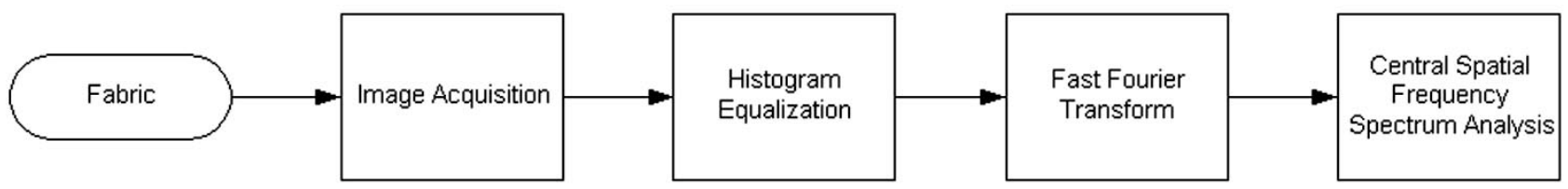

Fig. 7. System flow of fabric defect detection.

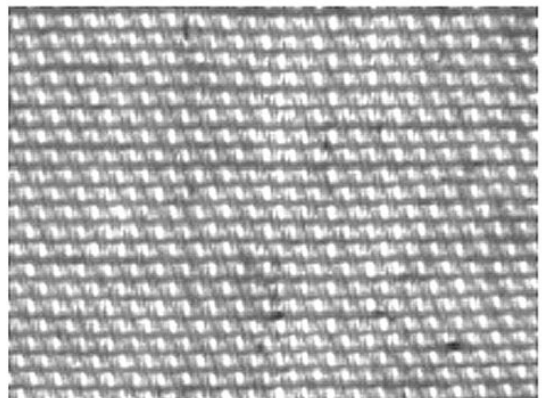

(a)

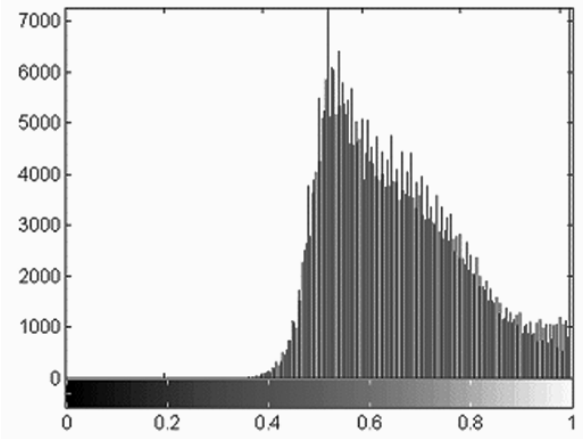

(c)

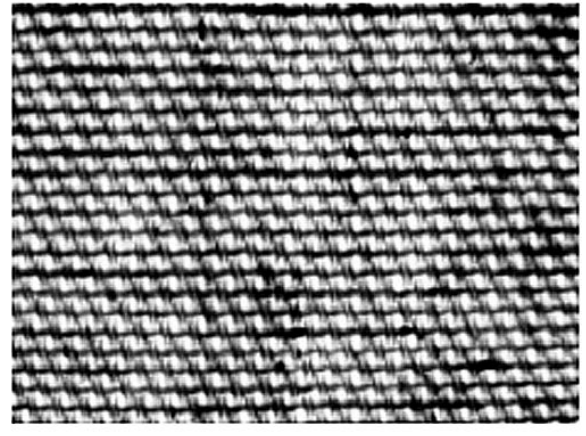

(b)

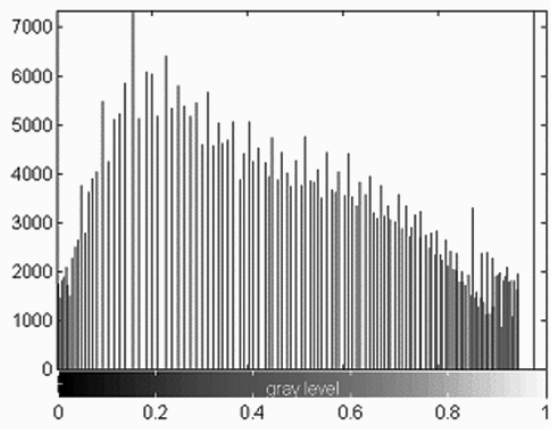

(d)

Fig. 8. Example of an image with gray-level histogram. (a) Original image. (b) Gray-level histogram of original image. (c) Image after equalization. (d) Gray-level histogram after equalization.

The difference between missing yarn and double yarn is their fabric threads count. Average light intensity P1 can show this characteristic. For missing yarn, higher $\mathbf{P 1}$ is expected because there is less thread in this defect. Broken fabric and yarn densities variation (low or high fabric density) are a change of periodicity in both $x$ and $y$ axes, and both $\left|F\left(f_{x}, 0\right)\right|$ and $\left|F\left(0, f_{y}\right)\right|$ diagrams are mostly changed.

In the broken fabric, $\mathbf{P 3}$ and $\mathbf{P 6}$ values are not changed. This is because this defect is an instant change of the fabric density, and it only affects P1, P2, P4, P5, and P7 values. The P1 is high because the fabric is broken, and leads to increase of light intensity. For the low fabric density, $\mathbf{P 3}$ and $\mathbf{P 6}$ are lower because the numbers of thread are decreased. The thread width may be changed in this defect. Therefore, P1, P2, P4, P5, and P7 are not applicable to detect these defect characteristics. Details of the expected results are summarized below.

\section{EXPERIMENTAL SETUP}

\section{A. Image Acquisition}

In this study, plain white fabrics are used. Defects with double yarn, missing yarn, web and fabric density variation
TABLE I

Difference in Parameters PRedicted Between the Fabric AND ITS DEFECT

\begin{tabular}{|c|c|c|c|c|c|c|c|}
\hline & $\mathbf{P 1}$ & $\mathbf{P} 2$ & $\mathbf{P 3}$ & P4 & P5 & P6 & P7 \\
\hline $\begin{array}{l}\text { Double (Fill) } \\
\text { yarn }\end{array}$ & $\mathrm{L}$ & $\mathrm{L}$ & $\overline{\mathrm{NC}}$ & $\overline{\mathbf{H}}$ & $\overline{N C}$ & $\overline{N C}$ & $\overline{\mathrm{NC}}$ \\
\hline $\begin{array}{l}\text { Double } \\
\text { (Wrap) yarn }\end{array}$ & $\mathrm{L}$ & NC & NC & NC & L & NC & $\mathrm{H}$ \\
\hline $\begin{array}{l}\text { Missing (Fili) } \\
\text { yarn }\end{array}$ & $\mathrm{H}$ & $\mathrm{L}$ & NC & H & NC & NC & $\mathrm{NC}$ \\
\hline $\begin{array}{l}\text { Missing } \\
\text { (Wrap) yarn }\end{array}$ & $\overline{\mathrm{H}}$ & $\mathrm{NC}$ & NC & $\mathrm{NC}$ & $\bar{L}$ & $\overline{N C}$ & $\overline{\mathrm{H}}$ \\
\hline Broken Fabric & $\mathrm{H}$ & L & NC & $\mathrm{H}$ & L & $\mathrm{NC}$ & $\mathrm{H}$ \\
\hline $\begin{array}{l}\text { Low fabric } \\
\text { density }\end{array}$ & $\mathrm{NA}$ & $\mathrm{NA}$ & $\mathrm{L}$ & NA & NA & $\mathrm{L}$ & NA \\
\hline $\begin{array}{l}\text { High fabric } \\
\text { density }\end{array}$ & NA & NA & H & NA & NA & $\mathrm{H}$ & NA \\
\hline
\end{tabular}

H: Higher, L: Lower, NC: no change, NA: Not applicable

were inspected and compared with the faultless fabric. The image acquisition system includes a personal computer (Pentium-200MMX), frame grabber, CMOS imager, and a system monitor. The fabric image is captured by a CMOS imager, and a frame grabber digitizes the video signal into a $768 * 576$ 

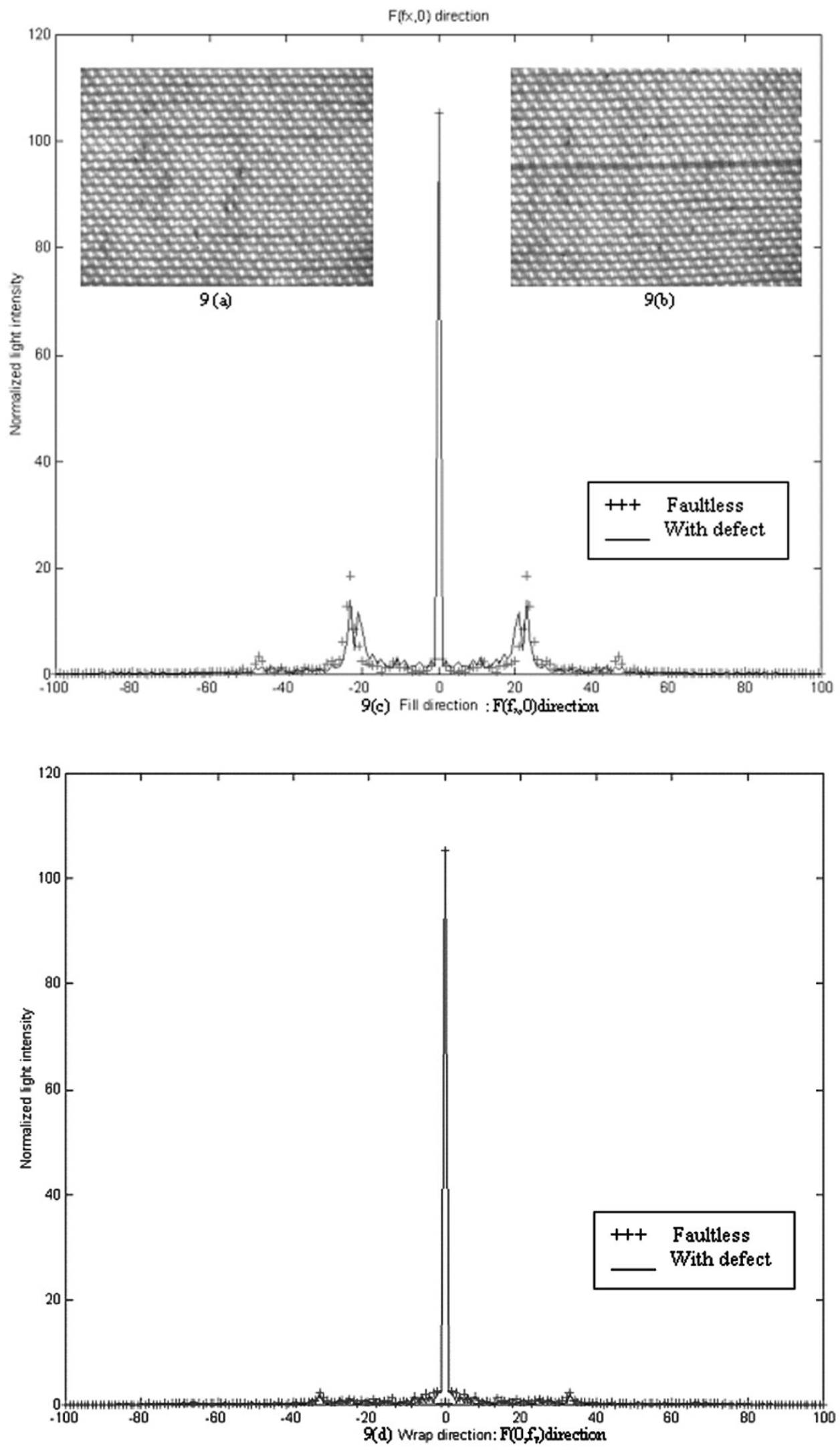

Fig. 9. (a) Faultless fabric. (b) Double fill. (c) Their fill direction spectrum. (d) Their wrap direction spectrum.

pixel with 8-bit gray-level resolution image and stores it into computer memory. This image data is then processed by the defect detection procedures as shown in Fig. 7. Backlighting illumination is used to achieve the high-contrast fabric images. 


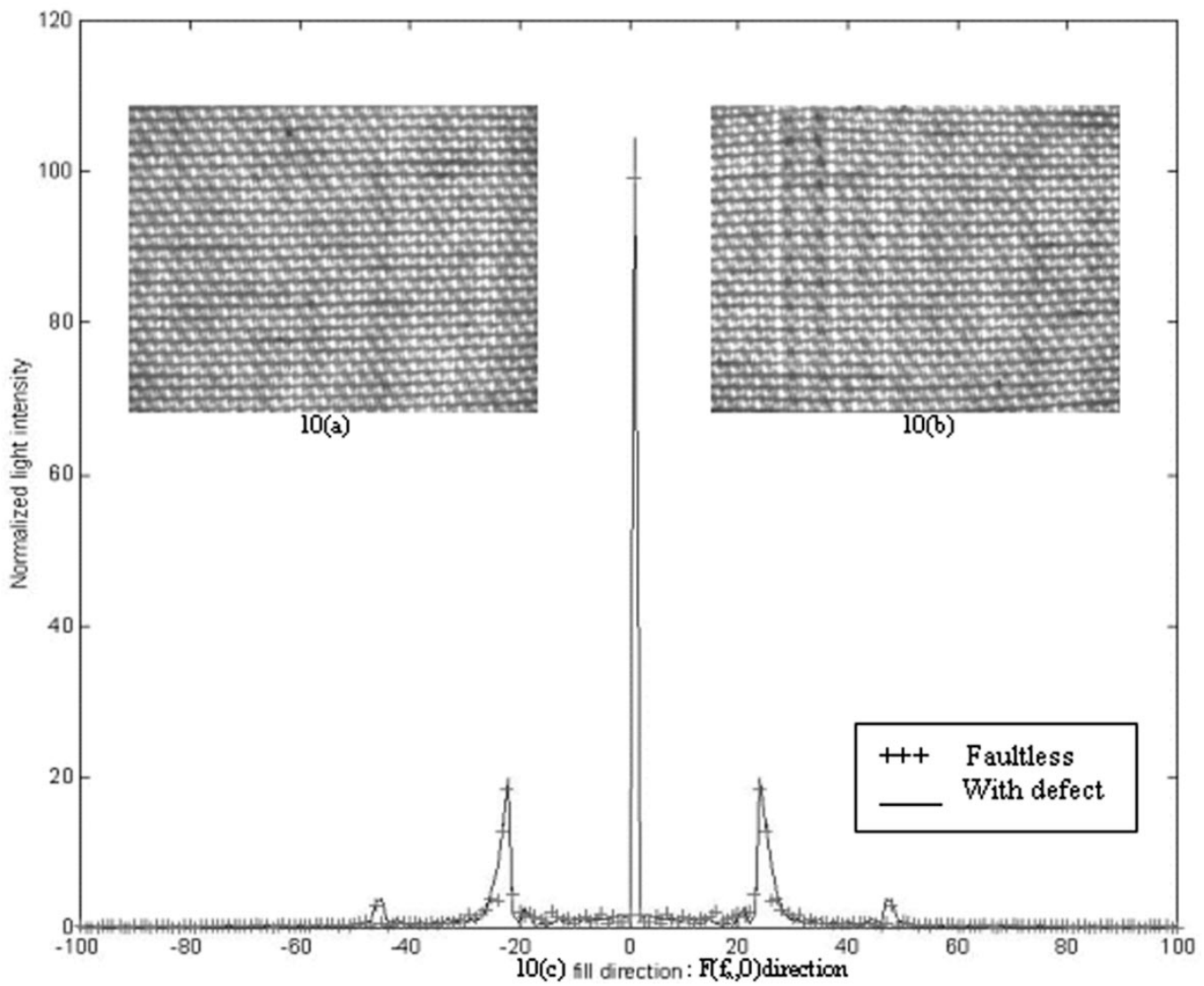

Fig. 10. (a) Faultless fabric. (b) Missing wrap. (c) Their fill direction spectrum.

\section{B. Histogram Equalization}

Histogram equalization is performed to obtain a uniform density image histogram [12], [13]. This process extends the dynamic range of gray levels and increases the image contrast. The aim is to standardize the brightness and contrast of the images. Fig. 8 gives an example of using equalization to improve the overall brightness and contrast of an image.

\section{FFT}

An FFT (two-point) is used [12], [13] for fast computation, which means that the image size is cut to $512 \times 512$ pixels in our experiment. This is because the image length and width should be a power of two. The software package Matlab [14] is used for this experiment. After the Fourier transform, the central spatial frequency spectrum diagram is extracted from the threedimensional diagram. A real sample of double fill and its central spatial frequency spectrum diagrams are shown in Fig. 9(b)-(d).

By observing these two diagrams [Fig. 9(c) and (d)] and comparing them with the simulated diagrams of double wrap in Fig. 6(b) and (c), the orientation of the defect mainly affects the relevant diagram. For example, double wrap affects the parameters in the $\left|F\left(0, f_{y}\right)\right|$ diagram, and double fill mainly affects the parameters in the $\left|F\left(f_{x}, 0\right)\right|$ diagram. However, the high spatial frequency peaks in Fig. 9(b) and (c) are loosely localized and embedded with some noise. A number of reasons can explain this result. For example, the surface tufts give a random textured component in the fabric images that distort the periodic structure. In addition, the illumination fluctuation gives high-frequency noise background. Because of these effects, only parameters around the central peaks and the first peaks can be extracted for defect characteristics.

Another example of defect detection is given in Fig. 10. Fig. 10(b) shows a real defect sample of missing (wrap) yarn. The brighter spots that form a vertical line is caused by the missing yarn. From Table I, the parameters in the $\left|F\left(0, f_{y}\right)\right|$ diagram would be affected and this is confirmed by Fig. 10(d). The first peak value of the defect case is lower than the faultless fabric, which is reflected by calculating the parameter P5.

\section{RESULTS}

Experimental results are used to verify the proposed approach. In this experiment, four defect models and their corresponding real samples are used to examine this approach. Table II gives the difference in parameters obtained between simulated fabric and its defect. The results in Table II follow our expectation summarized earlier in Table I.

Table III gives the results of using real fabric samples. The results follow very well with our expectation. Missing wrap is an example for describing these parameters. Since this defect is missing one or more vertical threads, it only occurs in the $\left|F\left(0, f_{y}\right)\right|$ diagram. Therefore, the significant parameters should be P1, P5, P6, and P7. Since the fabric thread count is lower than the faultless fabric, the average light intensity of defect is higher. Due to this reason, P1 should, therefore, be higher. 


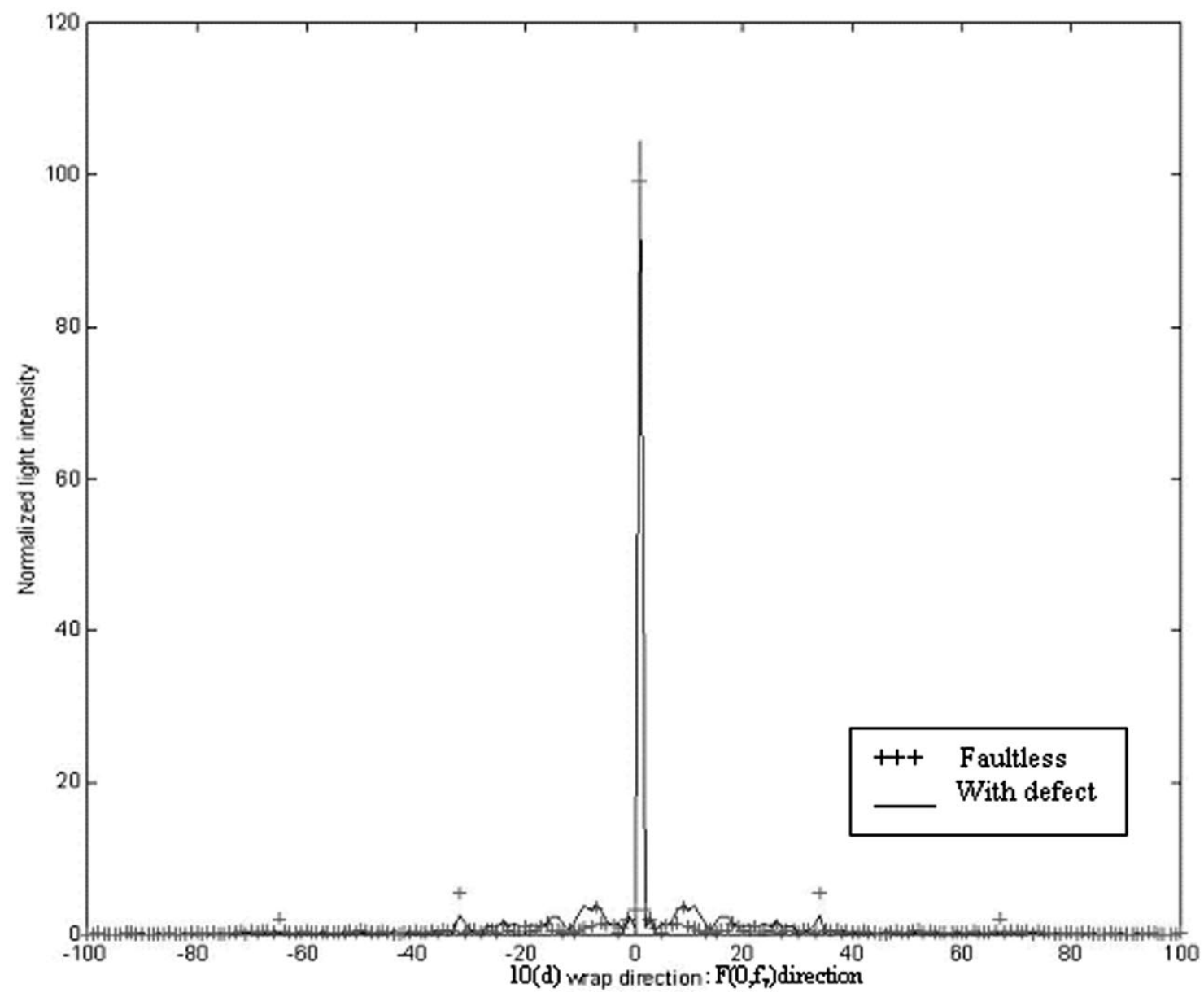

Fig. 10. (Continued.) (d) Their wrap direction spectrum.

TABLE II

DifFerence in Parameters ObTained Between a Simulated Fabric MODEL AND ITS DEFECT

\begin{tabular}{|c|c|c|c|c|c|c|c|}
\hline & $\mathbf{P 1}$ & $P_{2}$ & P3 & PA & P5 & P6 & P7 \\
\hline $\begin{array}{l}\text { Double } \\
\text { (Wrap) } \\
\text { yarn }\end{array}$ & $\begin{array}{c}L \\
(-2.1)\end{array}$ & $\begin{array}{l}\text { NC } \\
(0)\end{array}$ & $\begin{array}{l}\mathrm{NC} \\
(0)\end{array}$ & $\begin{array}{l}\text { NC } \\
(0)\end{array}$ & $\frac{L}{(-14.4)}$ & $\begin{array}{l}\mathrm{NC} \\
(0)\end{array}$ & $\begin{array}{c}\mathrm{H} \\
(66.7)\end{array}$ \\
\hline $\begin{array}{l}\text { Missing } \\
\text { (Wrap) } \\
\text { yarn }\end{array}$ & $\begin{array}{c}H \\
(2.9)\end{array}$ & $\begin{array}{l}\text { NC } \\
(0)\end{array}$ & $\begin{array}{l}\text { NC } \\
(0)\end{array}$ & $\begin{array}{l}\text { NC } \\
(0)\end{array}$ & $\begin{array}{c}L \\
(-5.3)\end{array}$ & $\begin{array}{l}N C \\
(0)\end{array}$ & $\underset{(71.8)}{\mathrm{H}}$ \\
\hline $\begin{array}{l}\text { Broken } \\
\text { Fabric } \\
\text { (Web) }\end{array}$ & $\begin{array}{c}\mathbf{H} \\
(\mathbf{3 3} .4)\end{array}$ & $\begin{array}{c}\mathrm{L} \\
(-14.9)\end{array}$ & $\begin{array}{l}\text { NC } \\
(0)\end{array}$ & $\begin{array}{c}\mathbf{H} \\
(32.95)\end{array}$ & $\begin{array}{c}\mathbf{L} \\
(-24.2)\end{array}$ & $\begin{array}{l}\text { NC } \\
(0)\end{array}$ & $\underset{(25.5)}{\mathrm{H}}$ \\
\hline $\begin{array}{l}\text { Low } \\
\text { fabric } \\
\text { density }\end{array}$ & $\mathrm{NA}$ & NA & $\begin{array}{c}\mathrm{L} \\
(-8)\end{array}$ & NA & NA & $\begin{array}{c}\mathrm{L} \\
(-6)\end{array}$ & NA \\
\hline
\end{tabular}

In addition, due to the irregular texture in the wrap direction, the first peak value is decreased and ripple occurs, which would cause $\mathbf{P 5}$ to be lower and $\mathbf{P 7}$ higher. In summary, Tables II and III can be used to classify the fabric defect type by noting the changes in the parameters.

\section{CONCLUSIONS}

An approach based on Fourier transform has been described to detect the structural defect in fabric. The simulated models
TABLE III

DifFERENCE IN PARAMETERS OBTAINED BETWEen a REAL FABRIC AND ITS DEFECT

\begin{tabular}{|c|c|c|c|c|c|c|c|}
\hline & $\mathbf{P 1}$ & $\mathrm{P2}$ & $\mathrm{p3}$ & $\mathrm{P4}$ & P5 & P6 & P7 \\
\hline $\begin{array}{l}\text { Double } \\
\text { (fiil) } \\
\text { yarn }\end{array}$ & $\begin{array}{c}\mathrm{L} \\
(-1.8)\end{array}$ & $\frac{L}{(-3.9)}$ & $\begin{array}{l}\mathrm{NC} \\
(0)\end{array}$ & $\begin{array}{c}\mathrm{H} \\
(17.7)\end{array}$ & $\begin{array}{c}\mathrm{NC} \\
(-0.2)\end{array}$ & $\begin{array}{l}\mathrm{NC} \\
(0)\end{array}$ & $\begin{array}{c}\mathrm{NC} \\
(-1.5)\end{array}$ \\
\hline $\begin{array}{l}\text { Missing } \\
\text { (Wrap) } \\
\text { yarn }\end{array}$ & $\begin{array}{c}\mathrm{H} \\
(4,6)\end{array}$ & $\begin{array}{l}\overline{N C} \\
(1.0)\end{array}$ & $\begin{array}{l}\text { NC } \\
(0)\end{array}$ & $\begin{array}{l}\text { NC } \\
(-0.3)\end{array}$ & $\frac{1}{(-3,2)}$ & $\begin{array}{l}\text { NC } \\
(0)\end{array}$ & $\begin{array}{c}\mathbf{H} \\
(14.8)\end{array}$ \\
\hline $\begin{array}{l}\text { Broken } \\
\text { Fabric } \\
\text { (Web) }\end{array}$ & $\begin{array}{c}\mathrm{H} \\
(5.4)\end{array}$ & $\begin{array}{c}\mathrm{L} \\
(-11.6)\end{array}$ & $\begin{array}{l}\text { NC } \\
(0)\end{array}$ & $\begin{array}{c}\mathbf{H} \\
(10.4)\end{array}$ & $\begin{array}{c}\mathrm{L} \\
(-4.4)\end{array}$ & $\begin{array}{l}\text { NC } \\
\text { (5) }\end{array}$ & $\begin{array}{c}\mathrm{H} \\
\mathbf{( 8 . 4 )}\end{array}$ \\
\hline $\begin{array}{l}\text { High } \\
\text { fabric } \\
\text { density }\end{array}$ & $\begin{array}{c}\text { NA } \\
(-0.5)\end{array}$ & $\begin{array}{c}\text { NA } \\
(10.7)\end{array}$ & $\begin{array}{c}\text { H } \\
(18)\end{array}$ & $\begin{array}{l}\text { NA } \\
(2.0)\end{array}$ & $\begin{array}{c}\text { NA } \\
(-4,8)\end{array}$ & $\begin{array}{c}H \\
(42)\end{array}$ & $\begin{array}{l}\text { NA } \\
(7.1)\end{array}$ \\
\hline
\end{tabular}

are used to understand the behavior of frequency spectrum. Since the three-dimensional frequency spectrum is very difficult to analyze and many defects occur along the horizontal and vertical axes, the central spatial frequency spectrum approach has been proposed to increase the efficiency of the analysis process. Seven significant characteristic parameters can be extracted from the central spatial frequency spectrums for describing the defect type. Experiments have shown that the extracted parameters can be used to classify fabric defects. 


\section{REFERENCES}

[1] K. Srinivasan, P. H. Dastoor, P. Radhakrishnaiah, and S. Jayaraman, "FDAS: A knowledge-based framework for analysis of defects in woven textile structures," J. Textile Inst., pt. 1, vol. 83, no. 3, pp. 431-1448, 1992.

[2] K. Schicktanz, "Automatic fault detection possibilities on nonwoven fabrics," Melliand Textilberichte, vol. 74, pp. 294-295, 1993.

[3] X. F. Zhang and R. R. Bresee, "Fabric defect detection and classifiction using image analysis," Textile Res. J., vol. 65, no. 1, pp. 1-9, 1995.

[4] J. S. Lane and S. C. Moure, "Textile fabric inspection system," U.S. Patent 5774 177, 1998.

[5] C. Ciamberlini, F. Francini, P. Sansoni, and B. Tiribilli, "Defect detection in textured materials by optical filtering with structured detectors and self-adaptable masks," Opt. Eng., vol. 35, no. 3, pp. 838-844, 1996.

[6] C. Castellini, F. Francini, G. Longobardi, and B. Tiribilli, "On-line textile quality control using optical Fourier transforms," Opt. Lasers Eng., vol. 24, pp. 19-32, 1996.

[7] C. Ciamberlini, F. Francini, G. Longobardi, P. Poggi, P. Sansoni, and B. Tiribilli, "Weaving defect detection by Fourier imaging," Vis. Syst. Applicat. SPIE, vol. 2786, pp. 9-18, 1996.

[8] E. J. Wood, "Applying Fourier and associated transforms to pattern characterization in textiles," Textile Res. J., vol. 60, pp. 212-220, 1990.

[9] S. A. H. Ravandi and K. Toriumi, "Fourier transform analysis of plain weave fabric appearance," Textile Res. J., vol. 65, no. 11, pp. 676-683, 1995.

[10] J. Escofet, M. S. Millan, H. Abril, and E. Torrecilla, "Inspection of fabric resistance to abrasion by fouries analysis," Proc. SPIE, vol. 3490, pp. 207-210, 1998

[11] H. Sari-Saraf and J. S. Goddard, "On-line optical measurement and monitoring of yarn density in woven fabrics," Automat. Opt. Inspect. Ind. SPIE, vol. 2899, pp. 444-452, 1996.

[12] R. C. Gonzalez and R. E. Woods, "Image transforms," in Digital Image Processing. Reading, MA: Addison-Wesley, 1993, ch. 3, pp. $81-128$.

[13] R. C. Gonzalez and R. E. Woods, "Image enchancement," in Digital Image Processing. Reading, MA: Addison-Wesley, 1993, ch. 4, pp. 166-189.

[14] MATLAB User's Guide, The MathWorks Inc., Natick, MA, Aug. 1992.

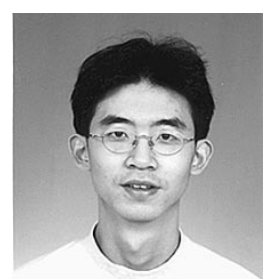

Chi-ho Chan (S'00) was born in Hong Kong. He received the B. Eng. degree in electrical and electronic engineering from the University of Bradford, Bradford, U.K., in 1997. He is currently working toward the M.Phil degree in electrical and electronic engineering at The University of Hong Kong, Hong Kong.

His major research interests include image processing and analysis.

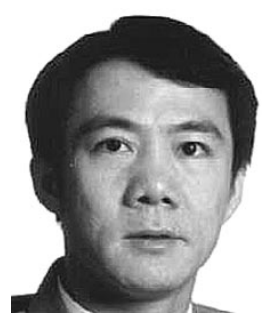

Grantham K. H. Pang (S'84-M'86) received the $\mathrm{Ph} . \mathrm{D}$. degree from the University of Cambridge, Cambridge, U.K., in 1986 for research in multivariable control system design and expert systems.

He was with the Department of Electrical and Computer Engineering, University of Waterloo, Waterloo, ON, Canada, from 1986 to $1996 . \mathrm{He}$ joined the Department of Electrical and Electronic Engineering, The University of Hong Kong, Hong Kong, in 1996. Since 1988, he has authored more than 80 published technical papers and has authored or coauthored three books. His research interests include expert systems for control system design, intelligent control, intelligent transportation systems, neural networks, control theory, and computer-aided design. In 1994, he was a Senior Visiting Researcher at the Hitachi Research Laboratory, Japan. He has acted as a Consultant to several companies, including Mitsubishi Electric Corporation, Japan, and Northern Telecom and Imperial Oil Ltd., Canada. He is an Editor of the International Journal of Intelligent Control and Systems. $\mathrm{He}$ is also an Editor of Control and Computers, published by the International Association of Science and Technology for Development (IASTED).

Dr. Pang was the Organizing Chair of the 1996 IEEE Symposium on Computer-Aided Control System Design. He was appointed by the President of the IEEE Control Systems Society as the Chair of the Technical Committee on Computer-Aided Control System Design (1993-1995). In 1989, he was awarded the ICI Prize for authorship of the best paper on the application of the theory of control published in the Transactions of the Institute of Measurement and Control. $\mathrm{He}$ is a Chartered Electrical Engineer in the U.K. and a member of the Institution of Electrical Engineers, U.K., and the Hong Kong Institution of Engineers. 